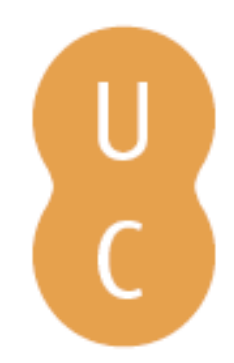

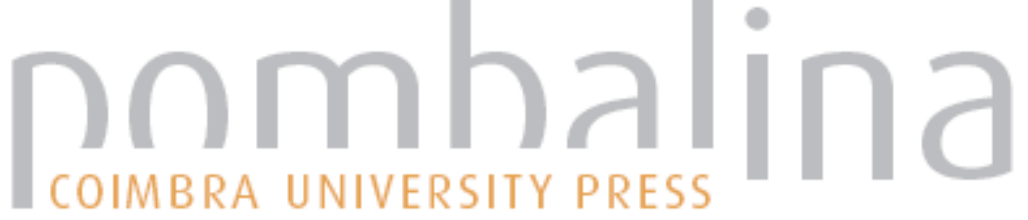

\section{As $\mathbf{4 0}$ horas de Angicos: uma experiência pedagógica de coautoria}

Autor(es): $\quad$ Silva, Francisco Canindé da; Sampaio, Marisa Narcizo

Publicado por: Imprensa da Universidade de Coimbra

URL

persistente: URI:http://hdl.handle.net/10316.2/41292

DOI: $\quad$ DOl:https://doi.org/10.14195/978-989-26-1326-0_3

Accessed : $\quad$ 26-Apr-2023 10:05:15

A navegação consulta e descarregamento dos títulos inseridos nas Bibliotecas Digitais UC Digitalis, UC Pombalina e UC Impactum, pressupõem a aceitação plena e sem reservas dos Termos e Condições de Uso destas Bibliotecas Digitais, disponíveis em https://digitalis.uc.pt/pt-pt/termos.

Conforme exposto nos referidos Termos e Condições de Uso, o descarregamento de títulos de acesso restrito requer uma licença válida de autorização devendo o utilizador aceder ao(s) documento(s) a partir de um endereço de IP da instituição detentora da supramencionada licença.

Ao utilizador é apenas permitido o descarregamento para uso pessoal, pelo que o emprego do(s) título(s) descarregado(s) para outro fim, designadamente comercial, carece de autorização do respetivo autor ou editor da obra.

Na medida em que todas as obras da UC Digitalis se encontram protegidas pelo Código do Direito de Autor e Direitos Conexos e demais legislação aplicável, toda a cópia, parcial ou total, deste documento, nos casos em que é legalmente admitida, deverá conter ou fazer-se acompanhar por este aviso. 


\title{
DIÁLOGOS REIREANOS
}

\section{A EDUCAÇÃO E FORMAÇÃO DE JOVENS E ADULTOS EM PORTUGAL E NO BRASIL}

\author{
Luís Alcoforado \\ Márcia Regina Barbosa \\ Denise Aparecida Brito Barreto \\ (editores)
}


3. AS 4O HORAS DE ANGICOS:

UMA EXPERIENCIA PEDAGÓGICA DE COAUTORIA

\author{
Francisco Canindé da Silva 6 \\ Marisa Narcizo Sampaio ${ }^{7}$
}

\title{
Resumo
}

Este texto assume como pano de fundo a experiência das 40 horas de Angicos, proposta de educação democratizadora e emancipatória iniciada por Paulo Freire no início da década de 1960 na cidade de Angicos, estado do Rio Grande do Norte - Brasil. Nesse contexto, a reflexão proposta funda-se na experiência dialógica da coautoria para analisar a forma como diferentes interlocutores, que se foram fazendo presentes no projeto ao longo da sua história (pesquisadores, estudantes universitários, professores, agentes culturais), foram amplificando as suas práticas e, ao mesmo tempo, (re)criando a proposta de alfabetização idealizada por Paulo Freire. Os indícios recolhidos advêm de entrevistas realizadas junto a estudantes e a coordenadores/

\footnotetext{
${ }^{6}$ Professor da Universidade do Estado do Rio Grande do Norte - Campus Avançado Prefeito Walter de Sá Leitão, Assu/RN. Doutorando do Programa de Pós-graduação em Educação - ProPEd da Universidade do Estado do Rio de Janeiro - UERJ. Endereço eletrônico: caninprof@hotmail.com

7 Professora adjunta da Universidade Federal do Rio Grande do Norte - UFRN. Coordenadora do Núcleo de Referência de História e Memória da Educação de Jovens e Adultos no Rio Grande do Norte. Endereço eletrônico: marisamns@gmail.com
} 
as na ocasião das comemorações do cinquentenário da experiência de Angicos. Reforçou-se, nesse sentido, uma postura de recuperar a história da experiência não apenas de um ponto de vista contemplativo, mas transformador, no intuito de informar como a história construiu o presente e inspira o futuro - uma das diretivas de ação das pesquisas do Núcleo de Referência em História e Memória da Educação de Jovens e Adultos no Rio Grande do Norte (NUHMEJA-RN).

\section{Abstract}

The framework of this paper takes place in the 40 boras de Angicos (40 hours of Angicos), an experience of democracy and empowerment started by Paulo Freire in the early 1960 in the city of Angicos, State of Rio Grande do Norte - Brazil. Within this context, the reflection purposed in the paper starts in the dialogic experience of co-authorship to analyze in what circumstances the different participants of the experience (researchers, college students, professors, cultural agents) were, over time, amplifying their practices and (re)creating the literacy purpose idealized by Paulo Freire. The evidences were gathered through interviews with students and coordinators during the celebration of the $50^{\text {th }}$ anniversary of the experience of Angicos. All the efforts highlight the importance of recover the history in a transformative way, analyzing how it built the present and how it inspires the future - that is one of the policies of the Núcleo de Referência em História e Memória da Educação de Jovens e Adultos no Rio Grande do Norte (NUHMEJA-RN - Center of Reference in History and Memory of Youth and Adult Education in Rio Grande do Norte). 
[...] a minha fala como coautor, como todos nós que fomos coordenadores e alunos, ao mesmo tempo, nas 40 horas, porque fomos os coautores das 40 horas. Partimos de uma teoria do Paulo, em alguns momentos aprendemos com a teoria do Paulo, em outros nossa prática questionou a teoria do Paulo, a nossa prática aperfeiçoou a teoria do Paulo, a nossa prática obrigou Paulo a rever alguns itens, não só Paulo, mas toda a equipe do centro. (Guerra, 2013)

Mas, repito, quem eram esses jovens entusiasmados e engajados com a alma nessa tarefa? Éramos jovens universitários, de diversas formações (filosofia, direito, pedagogia, farmácia, serviço social, medicina, jornalismo, odontologia, letras, etc.) e dois secundaristas de escola pública, Edilson Dias e Talvani Guedes, movidos por um forte idealismo que se revestia não só de boa vontade ou de teoria, mas, sobretudo, de capacidade para gerar ações conscientes, instigadoras e consequentes, apressados que éramos pelo muito que se tinha para ser, pensar e fazer. (Silva, 2013)

\section{Introdução}

As declarações acima transcritas, e que foram produzidas no ano de 2013 na cidade de Angicos/RN por ocasião das comemorações do cinquentenário da experiência de alfabetização de jovens e adultos conhecida como As 40 horas de Angicos, [grifo dos autores], indicam a nossa relação com essa experiência pedagógica de Paulo Freire e a abordagem singular que dela queremos fazer aqui.

Falamos da proposta de educação democratizadora e emancipatória, idealizada pelo educador Paulo Freire, e realizada com 300 pessoas jovens e adultas na cidade de Angicos, interior do Rio Grande do Norte, em 1963. Para Paulo Freire, a experiência 
significou uma oportunidade de concretizar a concepção político-pedagógica subjacente à sua proposta de alfabetização com um número expressivo de pessoas (a previsão - frustrada pelo golpe militar de 1964 - era de 100 mil pessoas), já que em Recife tinha realizado pequenas experiências para um público bem mais restrito, e acabou tendo um significado histórico, responsável por notabilizá-lo nacional e internacionalmente, tendo recebido defesas, apostas, créditos, recriações e emergências no Brasil e no mundo.

Para além de todas essas referências que o pensamento pedagógico freireano alcançou, e por todas as inferências já realizadas sobre esta experiência, que amiúde foi exposta e dialogada, nosso desejo é expandir as possibilidades de compreensão, e inventivamente criar outros modos de relacioná-la a práticas educativas atuais. Fazemos isso fundamentados nas pesquisas realizadas e em andamento sobre a história e memória da educação de jovens e adultos no Rio Grande do Norte, já que nosso trabalho, também feito em coautoria, se baseia nas pesquisas do Núcleo de História e Memória da EJA e da Educação Popular no RN, onde aprendemos que recuperar a memória não nos serve para ficar no passado, admirando os acontecimentos como numa vitrine cristalizada, mas que devemos dar vida a estes acontecimentos refletindo sobre sua importância na constituição do que somos hoje e para fazer a ponte com o presente e com o futuro, ensinando-nos, contribuindo com nossas produções atuais.

A coautoria anunciada no subtítulo do texto, e mencionada acima como uma característica deste texto, reivindica um olhar mais cuidadoso sobre as ações políticas e pedagógicas desenvolvidas naquele período por jovens estudantes que, mesmo sob a orientação de Paulo Freire, foram capazes de criar e recriar a proposta de alfabetização em sua gênese. A ideia de coautoria, embora percebida após 50 anos da experiência por seus rememoradores, esteve sempre presente na vivência cotidiana do projeto de alfabetização, envolvendo a prática de modo a refazê-la permanentemente. 
A todo momento que rememoram a experiência, seus protagonistas sempre evidenciam a relação dialógica da coautoria - ora, quando se relata acerca dos primeiros contatos, das conversas estabelecidas entre educadores e educandos, no recolhimento do universo vocabular, ora no debate entre os coordenadores de círculos de cultura nos planejamentos das aulas, e por vezes, quando dos encontros de formação com o próprio Paulo Freire.

Assim, compreendemos que a coautoria é um elemento implicador e definidor da experiência pedagógica de alfabetização com jovens e adultos em Angicos/RN, e, que a força sempre pulsante das 40 horas é resultante da intervenção autêntica e recursiva de todos os envolvidos que se fizeram parceiros naquela jornada de aprendizagens. Sem a coautoria, parece-nos que a polissemia de interpretações e retroalimentações da proposta não teria sido possível e, talvez não continuasse impulsionando tantas e tantas outras experiências de alfabetização.

É especialmente importante para nós que vivemos no Rio Grande do Norte termos a oportunidade de reafirmar e lembrar esse passado de ação pelo direito de todos à educação porque, hoje, mais de 50 anos depois, ainda temos que seguir nesta luta e precisamos de ações do poder público, em todas as suas esferas, e de mobilizações dos movimentos sociais que garantam o direito a uma educação de boa qualidade para todas as pessoas. Vivemos a necessidade de ressignificar a Educação de Jovens e Adultos, enfatizando seu caráter popular e ao mesmo tempo impulsionando as possibilidades de educação ao longo da vida para todos.

Neste intuito de rememorar a autoria e coautoria como uma dimensão pouco debatida da proposta pedagógica inovadora de alfabetização, especificamente aos que foram seus protagonistas, além de Paulo Freire: os estudantes e os coordenadores e coordenadoras de círculo de cultura, começamos registrando o que o 
próprio Freire $^{8}$ resumiu como sendo o significado dessa experiência, para ele mesmo (e para o mundo), em entrevista concedida no ano de 1993 durante as comemorações do trigésimo aniversário das quarenta horas:

Angicos não mudou o mundo, mas marcou. No futuro próximo, Angicos será compreendido como o ponto de transformação da educação brasileira. Aqui vivi meu aprendizado da relação teoria e prática que mudaria a minha trajetória profissional" (Freire, 1993 cit. por Silva, 2013, p. 9).

O depoimento nos chama atenção, especialmente quando Paulo Freire se refere ao aprendizado teórico/prático vivido, que posteriormente iria colocá-lo como referência de educação transformadora e libertadora. A declaração, representa em nossa compreensão um primeiro momento de coautoria - reconhecendo a relação teoria/ prática como indissociável. Assim, acreditamos que todos os participantes das 40 horas (estudantes, coordenadores/as) podem ser considerados coautores, visto que participaram efetivamente do movimento não-linear teoria/prática da ação alfabetizadora pensada inicialmente por Paulo Freire naquele período.

Com este espírito de preservar a memória para que ela informe e sirva de inspiração para as ações do presente, trabalhamos no Núcleo de Referência em História e Memória da Educação de Jovens e Adultos no Rio Grande do Norte (NUHMEJA-RN) e estivemos oportunamente presentes durante as comemorações do cinquentenário da experiência, conversando e entrevistando vários estudantes e coordenadoras de círculo de cultura de Angicos,

${ }^{8}$ Citadas por Valquíria Silva, em discurso na Câmara de Vereadores de Angicos agradecendo a homenagem recebida durante as comemorações do cinquentenário das 40 horas. 
na busca incessante de saber-mais destes coautores. Nestes encontros pudemos ouvir de perto de cada um dos entrevistados vários depoimentos sobre como viveram esta experiência, como foram atravessados/modificados por ela e como atravessaram-na/modificando-a.

Implicados por esse sentimento de interação entre os sujeitos praticantespensantes ${ }^{9}$ discutimos, a partir de noções que se complementam, o papel dos coautores exercido pelos protagonistas das 40 horas de Angicos, articulando-as simultaneamente à noção de diálogo, fundante na obra de Paulo Freire; à noção de experiência discutida por Jorge Larrosa (2002); e à noção de praticantes em Michel de Certeau (2011). Cada uma dessas leituras epistemológicas no tecer do texto ajuda-nos a traduzir questões anteriormente não percebidas, ao mesmo tempo em que, visibilizando-as, corporificamos outras reflexões ao já dito sobre a experiência.

\section{Diálogo com a experiência}

A prática do diálogo marcou definitivamente a vida de cada um dos homens e mulheres envolvidos com a experiência - foi o contato, a com-versa, casa a casa, entre pessoas, nos espaçostempos de uso dos praticantespensantes $\mathrm{do} / \mathrm{no} / \mathrm{com}$ o mundo que autorizou o desenvolvimento da ação pedagógica de forma tão intensiva e autêntica. O diálogo permitiu que os homens e mulheres sem o domínio inicial do sistema alfabético fossem vistos não somente como alunos, passivos e esvaziados de conteúdo; contrariamente, os jovens

9 Neste trabalho a grafia de alguns termos unificados expressa nosso entendimento de que esses elementos são indissociáveis. No caso de praticantespensantes em concordância com Oliveira (2012). 
universitários, potenciais coordenadores de círculos de cultura, no envolvimento direto e ativo com estas pessoas reconheciam por meio dessas conversas amistosas, o ofício de cada homem e mulher, diferenciando-se de propostas de alfabetização mais fechadas em que o diálogo não ocorre entre duas pessoas, mas a informação é transmitida de uma pessoa para outra.

Atualmente, quando vivenciamos em nosso país e em muitos países latino-americanos a efetivação da democracia, acentuada pela multiplicidade de marchas, dos movimentos de rua, de gente que se manifesta e luta por seus direitos, percebemos que a utopia lançada por Paulo Freire a partir da experiência das 40 horas - alfabetização como ato de liberdade - é cada vez mais viva, pulsante, necessária e, por isso, apresenta-se sempre desafiadora a todos nós educadores/as do mundo.

Assim, compreendemos que essa experiência nos toca, convoca e suscita o desejo de continuar aprendendo a partir dela, afinal, como nos ensina Larrosa (2002) muitas coisas têm acontecido, mas poucas têm força de uma experiência. São muitas as apostas feitas em métodos de alfabetização de adultos, mas estas tem se constituído, segundo o referido autor como excesso de informação, por seu caráter efêmero, fugaz e distanciado da prática cotidiana dos sujeitos.

A experiência é, portanto, nesse trajeto de buscas e construção compreensiva das 40 horas de Angicos, um outro dispositivo de força que percebemos favorável no processo de rememoração. Com ela identificamos indícios, sinais e pistas (Ginzburg, 2012) que nos ajudam a pensar a coautoria presente na proposição de alfabetização, astutamente trançada por Freire no início da década de sessenta do século passado.

Valendo-nos mais uma vez de Larrosa (2002) para exprimir o nosso entendimento e a importância que a experiência representa nesse trajeto de lembranças e de não esquecimento, pensamos que: 
Em qualquer caso, seja como território de passagem, seja como lugar de chegada ou como espaço do acontecer, o sujeito da experiência se define não por sua atividade, mas por sua passividade, por sua receptividade, por sua disponibilidade, por sua abertura. (p. 10)

O que via de uso entendemos por experiência parecia sustentar em Paulo Freire toda uma arte de alfabetizar e educar. E a defesa desta como que uma necessidade básica para quem deseja alfabetizar/educar horizontalmente, com paixão e criticidade. Desse modo, defendia, para si e para o grupo, o diálogo com as experiências de vida de cada homem e mulher; embrenhava-se no conflituoso campo da existência para alcançar os sistemas de interesse e de mobilização humana e social de cada estudante e, quando alcançava a vida pela experiência, problematizava com seus (co)autores.

As experiências, traduzidas em palavras geradoras e expressadoras de concepções de mundo, sinalizavam para ações encarnadas dos praticantespensantes da vida e significaram astúcias inventivas no processo de viver, tecendo outras relações e outra lógica - dialógica - no processo de formar pessoas, que por isso são coautoras deste processo. Nesse sentido consolidaram-se também em rebeldias resistentes aos modos econômicos, políticos e culturais imperativos aos que não sabiam ler/escrever a palavra dita; são transgressivas da lógica binária escolar - ensinar/aprender e rompem com formas historicamente determinadas de produção de saber (Certeau, 2011).

A seguir pretendemos apresentar estas pessoas, protagonistas, praticantespensantes [ênfase adicionada] e coautores das 40 horas de Angicos, e deixar que elas tomem voz neste texto, mostrando como, a partir do diálogo, inventaram, fizeram, modificaram e se deixaram modificar por esta experiência. 


\section{Conversas com os coautores - primeiras aproximações, novos enredamentos}

Tomando por base um dos princípios filosóficos de Paulo Freire - o diálogo, pensamos os percursos metodológicos do trabalho de pesquisa, alinhado as intenções do NUHMEJA e as reais condições de cada pessoa que estabeleceríamos conversas rememorativas. Traçamos a priori agendas de visitas em seus locais de vivência e, mesmo antes de entrevistá-los mantivemos um primeiro contato para saber das possibilidades e disponibilidade a este processo de rememorar. Foram várias as idas e vindas feitas com esses homens e mulheres que autodenominaram-se de coautores, mas diferentemente de outras proposições de pesquisa, fomos de perto estar com cada um deles, para que a conversa e as rememorações fossem descritas com mais espontaneidade, como de quem conta história.

Neste sentido, também realizamos, a exemplo do que fizeram os jovens universitários naquele período, visitas as residências de estudantes e coordenadores de círculos de cultura, estabelecendo diálogos rememorativos, sempre na tentativa de entender o que foi a experiência para cada um deles, e de que modo ela contribuiu para sua transformação pessoal e social.

As entrevistas foram feitas com as então alunas da experiência Francisca de França Germano; Idália Marrocos da Silva; Luzia de Andrade; Maria Eneide de Araújo Melo; Maria Luzia da Silva Andrade; Maria Miranda Gomes; Maria Pequena de Souza; Valdice Ivonete da Costa Santos; Zélia Irene da Silva; e com o coordenador de círculos de cultura Pedro Neves Cavalcante e as coordenadoras Lenira Leite Matos da Costa, Rosali Maria Liberato Cavalcante e Dilma Ferreira Lima. Pedro e Rosali, noivos em 1963 e hoje casados, foram entrevistados juntos na varanda de sua casa em Natal. As entrevistas que realizamos seguiram uma dinâmica menos rígida e controlada de perguntas e respostas, pois tentamos empreender o que Thompson 
(1992, p. 255) descreve como "uma 'conversa' livre em que a 'pessoa', o 'portador-de-tradição', a 'testemunha', ou o 'narrador' é 'convidado a falar' sobre um assunto de interesse comum".

Por meio dos relatos dos entrevistados percebemos diferentes memórias sobre o mesmo evento e entendemos que todas contribuem para formar um cenário dos acontecimentos, já que sabemos não existir uma verdade absoluta, mas, sim, versões sobre os acontecimentos que estão sempre conduzidas pelas histórias de vida, a

subjetividade, também atravessadas pela memória coletiva (Halbwachs, 1990) e pelas relações de poder que acabam por definir o que é ou não valorizado e até considerado verdade (Costa, 2007). Por isso podemos dizer que estas memórias individuais que registramos estão atravessadas pela memória coletiva, por aquilo que se aprendeu, se discutiu e se valorizou a respeito da experiência das 40 horas.

Além de registrar a memória e nos permitir produzir conhecimento sobre a experiência de Angicos e seus ensinamentos, entrevistar estes protagonistas significou também valorizar a voz dessas pessoas, as suas vivências e seus saberes, considerando-os como praticantespensantes [ênfase adicionada], produtores de um conhecimento a partir de suas práticas e, ao mesmo tempo, faz com que suas trajetórias tenham visibilidade e não se percam, mas tenham o seu lugar na história.

\section{Os coordenadores dos círculos de cultura - jovens na experiência do ser-querer-saber mais}

A equipe de coordenadores foi formada por 19 estudantes universitários, de diversas áreas e dois estudantes secundaristas, que se engajaram no projeto por motivos políticos (participar em um projeto que concretizava ideais de emancipação e justiça social) e pessoais (acompanhar amigos) (Sampaio \& Silva, 2013). Para a maioria, a 
participação nesta experiência foi uma lição de vida e oportunidade de muitas aprendizagens. Contam essa história com envolvimento pessoal e compromisso forjado na formação que tiveram, no próprio processo educativo e na convivência com os companheiros e com os alunos e alunas. É certo que se tornaram mais que companheiros, amigos, cúmplices, que tiveram suas vidas marcadas pela participação nesta experiência, pessoas que se colocaram como aprendizes, com Paulo Freire, da sua simplicidade, da sua maneira de conduzir o processo, de se relacionar com as surpresas e imprevistos, tomando-as como contribuição da prática para engravidar a teoria e modificá-la. Consideram-se também aprendizes com os educandos sobre a vida e sobre seus processos de aprendizagem.

\section{Jovens e adultos alfabetizandos da palavramundo: quem são? o que esperançam?}

Homens e mulheres unidos pela dureza do trabalho na agricultura, para o patrão e para subsistência, porém, sujeitos singulares, cada um com sua história. Pessoas que foram costituindo outras formas de existência, driblando com as táticas cotidianas (Certeau, 2011) as imposições feitas de cima para baixo e de fora para dentro pela ordem do discurso e da organização social hegemônica. Homens e mulheres de vida tecida na resistência, nos inusitamentos, na inventividade emergente e fugaz. Elaboram, segundo eles, com muita dificuldade suas formas de ser/estar no mundo e acreditam sempre na possibilidade de dias melhores, lutam por uma vida mais digna e menos controlada pela hegemonia de um pequeno grupo político-econômico.

As nove mulheres que entrevistamos contaram sua trajetória de agricultoras, pobres, marcadas ainda mais pela condição de ser mulher no interior do Nordeste, pois, além de não terem o direito de frequentar a escola pela falta dela ou pelo excesso de trabalho 
desde cedo, também não tinham este direito por serem mulheres. Esta condição marca, especialmente, uma das entrevistadas que, filha de fazendeiro, nos conta que não foi à escola por escolha da própria mãe, para não aprender a escrever para o namorado: "[...] lá tinha uma escola de uma tia minha e era num tempo que os pais não botavam as filhas para estudar, pra não aprender a ler e escrever para os namorados". (SOUZA, 2013).

A interlocução com as alfabetizandas das 40 horas, após 50 anos da experiência, permitiu-nos compreendê-las melhor a partir do lugar onde vivenciaram o movimento. São pessoas de um cotidiano muito desprovido de meios básicos de sobrevivência, tais como: atendimento público de saúde, saneamento básico, moradia digna e tantas outras, muito importantes para a qualidade de vida. O que ainda é muito comum observarmos em suas falas é a capacidade da alegria e da esperança, a utopia como pensam a vida e o mundo, com a mesma intensidade como pensaram no período da experiência. Algumas delas, com idade já bastante avançada, como é o caso de D. Idália (83 anos), demonstra uma disposição de vida e disponibilidade de participação, de fato, bastante ativa.

\section{Os praticantespensantes e sua relação de coautoria}

Para pensar os participantes da experiência de Angicos como coautores, conforme intentamos aqui, cremos que é preciso ir à gênese deste movimento, reconhecendo e reafirmando seu caráter popular, colocando Paulo Freire e sua proposta de educação como produções do seu tempo extremamente buliçoso e de mudanças intensas no contexto político-econômico e cultural do Brasil. A proposta de Freire era parte deste movimento e coerente com o espírito dos anos 50: para construir um país desenvolvido era preciso um novo sujeito, participante (também coautor) dessa construção. 
A educação popular construída naqueles anos é uma educação comprometida e orientada pela perspectiva dos direitos e da participação do povo, cuja dimensão política está na busca por uma sociedade democrática, por isso tem o diálogo como metodologia (Melo Neto, 2002). Como uma proposta nascida no bojo dos movimentos sociais da época, o sistema de educação pensado por Paulo Freire tem o diálogo como sua forma privilegiada de atuação sendo um de seus princípios fundamentais. Praticar o diálogo representa um esforço contra-hegemônico, na medida em que o sujeito de diálogo é um sujeito crítico que conhece seu poder de criar e de transformar (Freire, 1987). A noção de diálogo traz para a educação uma outra forma de se pensarfazer [ênfase adicionada] a relação pedagógica, que pressupõe uma horizontalização das relações, tornando-as mais democráticas, em que todos são vistos e considerados como sujeitos valorizados no seu conhecimento e cultura, que têm voz e podem contribuir para as construções coletivas. Assim, pudemos perceber elementos dessa concepção e sua perspectiva popular e democrática atravessando o cotidiano pedagógico das " 40 horas de Angicos" desde o início.

Para os coordenadores de círculos de cultura em Angicos, a experiência começou com a participação na pesquisa do universo vocabular daquela comunidade que definiria as palavras geradoras, uma maneira de se aproximar da cultura e dos conhecimentos dos educandos. Um movimento na direção do outro, típico de um processo dialógico, visto que com as palavras geradoras partia-se da visão de mundo dos educandos e da sua forma de expressá-la e pronunciá-la, para só então construir o material didático. A oportunidade de ir às casas e conversar com os possíveis educandos era formativa no sentido de experimentar o diálogo, conhecer os educandos, seu contexto de vida e seus conhecimentos. Para os educandos foi um momento de valorização de seus saberes/fazeres/ poderes como sujeitos de identidade, que algumas das entrevistadas 
traduzem dizendo que aquilo foi algo nunca visto: alguém bater à sua porta para conversar e oferecer alfabetização.

Anos depois, esta prática dialógica foi sistematizada em teoria que correu o mundo: na Pedagogia do Oprimido (1987) o diálogo é considerado princípio para a educação, pensando, naquele momento, especialmente na Educação de Jovens e Adultos, por ser a educação destinada às pessoas que foram, e são, historicamente marginalizadas na sociedade brasileira, aos oprimidos como Paulo Freire os nomeia. Para ele, permanecer com uma educação antidialógica é continuar formando uma sociedade de "oprimidos, com tudo acomodados e adaptados, 'imersos' na própria engrenagem da estrutura dominadora, temem liberdade, enquanto não se sentem capazes de correr o risco de assumi-la" (Freire, 1987, p.19). O diálogo é, então, parte de uma educação libertadora de quem é socialmente oprimido.

A concepção político-pedagógica de educação libertadora orientada pelo diálogo era a base do trabalho nos círculos de cultura em Angicos. Vivendo nos círculos uma relação pedagógica horizontal em que todos aprendem e ensinam, exigindo novamente o reconhecimento da importância do outro e a prática da dialogicidade, que transforma o espaço educativo em um lugar de colaboração, cooperação e interação, com pessoas que pensam na realidade como um todo, não somente na sua própria experiência, os protagonistas de Angicos impregnaram-se dessa práxis e empoderaram-se como coautores dessa proposta porque a experimentaram no sentido que Larrosa (2012) nos convida a entender: deixaram-se atravessar e modificaram-na com suas ações, dúvidas, inquietações, invenções, insubordinações, questionamentos, insurgências.

Também Certeau (1994) nos ajuda neste intento de compreender os educadores e educandos como coautores desta experiência de Angicos, já que ele nos ensina a concebê-los como praticantespensantes [ênfase adicionada] nas suas práticas cotidianas. Certeau nos fala do poder das pessoas comuns, vistas muitas vezes como 
consumidoras passivas do mundo, que inventam maneiras de fazer diferentes das prescritas ou esperadas. Ao desvelar o cotidiano como espaço/tempo de produção de distintas formas de agir sobre o contexto, ele nos ajuda a pensar as ações cotidianas e seus praticantes como sujeitos produtores de diversas maneiras de compreender e de fazer o mundo, reapropriando-se do que está dado.

Ao conversar com os coordenadores de círculos de cultura e ouvir suas memórias, vimo-nos diante de suas táticas e astúcias, inventando uma multiplicidade de práticas cotidianas, criando ações e proposições outras que foram conformando, dando vida à experiência, tornando-a o que foi, aquilo que conhecemos e admiramos hoje.

Com os relatos desses hoje senhores e senhoras que foram moços estudantes sobre o uso que fizeram do que aprenderam no curso preparatório e nos ensinamentos de Freire e sua equipe, aprendemos como eles foram constituindo e forjando uma prática pedagógica própria que julgavam mais adequada para aquele momento, para aquele grupo de educandos, com os objetivos que tinham. Como educadores e educadoras eles eram sujeitos do seu saber e da sua prática, criavam novas formas de ensinar, novos materiais, para além do que havia sido planejado inicialmente. A prática engravidava a teoria e a modificava.

Em suas narrativas sobre essa experiência eles descrevem uma rotina diária que permitiu e facilitou esse trabalho coletivo e a dinâmica de refletir sobre a teoriaprática [ênfase adicionada].

Diariamente pela manhã eles se reuniam para discutir os acontecimentos das aulas da noite anterior. Neste momento trocavam suas experiências e consideravam o pronunciamento da visão de mundo e dos conhecimentos dos alunos para pensar como continuar conduzindo as aulas. A formação que tinham recebido no curso, as orientações de Freire e sua equipe eram (re)estudados para subsidiar as decisões. À tarde voltavam a se reunir para ela- 
borar o planejamento mesmo da aula daquela noite, já nutridos da discussão da manhã, seus estudos e suas decisões.

Era um regime intenso, marcado pelo diálogo: relação entre sujeitos; troca de sentidos; interação; abertura ao outro; base para a aprendizagem de como atuar como educador.

Em alguns destes dias de trabalho esteve presente Paulo Freire que se entusiasmava com as descobertas da prática e as criações daqueles estudantes para dar conta de seus imprevistos. Eles eram sujeitos que, no diálogo com os sujeitos estudantes, estavam pronunciando sua palavra, criando sua práxis, modificando "seu mundo" e, muitas vezes, a própria proposta teórico-metodológica. Paulo Freire se colocava da mesma maneira: era ele mesmo um sujeito aberto ao diálogo sobre sua teoria com os coordenadores e sua prática.

Este processo dialógico no trabalho coletivo permitiu a reflexão conjunta que provocou aprimoramento, confirmação, negação, formulação e reformulação teórica e prática, concretizando a relação teoriaprática, tornando os coordenadores, segundo Silva (2013) frisa, parceiros de sua criação [ênfases adicionadas]. Os princípios freireanos do incabamento, da valorização do outro e do diálogo fundamentaram uma prática que favorecia a percepção de todos, educandos e educadores, como sujeitos produtores de conhecimento e de cultura, praticantespensantes, autorizados com essa e nessa prática a serem coautores do que viviam, experimentavam e criavam.

Com sua sede de saber e inquietude os educandos e educandas também cumpriram papel primordial neste engravidamento, já eram as insurgências de seu conhecimento colocadas em diálogo com o oferecido pelos educadores que os colocava em cheque, diante do inusitado e sobre este desafio tinham que trabalhar, inventar.

Na obra de Paulo Freire, engravidada pela prática em Angicos, o diálogo e a relação com o outro se materializa pela palavra, uma palavra que não é só o meio de comunicação, mas é também ação e reflexão, é práxis. Por esta palavra, que ele chama de verdadeira, 
se pronuncia o mundo, modificando-o, e "o mundo pronunciado, por sua vez, se volta problematizado aos sujeitos pronunciantes a exigir deles novo pronunciar" (Freire, 1987, p.90). Os sujeitos envolvidos nesse processo, concebidos e sentidos por nós, e por eles mesmos, como coautores da experiência de Angicos, vivenciaram esse pronunciamento ao não se restringirem a aplicar os ensinamentos recebidos. Leram (no sentido freireano), usaram (no sentido certeauniano) os conhecimentos aprendidos na sua preparação para realizar o ofício de educadores, e jogaram-se na experiência abertamente, dispostamente (como entende Larrosa), recriando aquilo que Paulo Freire os ofereceu.

O gérmen, porém, para esta (re)criação pode se encontrar no comprometimento político da maioria dos coordenadores e coordenadoras e na formação que receberam, que os permitiu pensarfazer além. Depois de participar do levantamento das palavras geradoras, os coordenadores de círculos de cultura fizeram um curso de formação com Paulo Freire e sua equipe do Serviço de Extensão Cultural (SEC), da então Universidade do Recife. Esse curso, realizado semanas antes de iniciarem o trabalho com os educandos, trazia orientações sobre aspectos sociológicos como realidade, economia e cultura brasileiras; aspectos políticos como planificação do desenvolvimento e processo de desalienação; um panorama geral da educação brasileira; e aspectos educativos a respeito do método, elaboração do material audiovisual, pesquisa vocabular, seleção das palavras geradoras e preparo de fichas, e ainda prática e metodologia do ensino (Lyra, 1996).

O que nos chama a atenção são os conteúdos que mesclam a atenção aos aspectos técnico-metodológicos do trabalho docente com a imprescindível reflexão político-cultural sobre a realidade do Brasil e dos educandos. Portanto, algo que foi formulado anos depois - a visão muldimensional sobre o processos de aprendizagem e sobre a prática pedagógica - já estavam aí presentes: humanização, 
politização, cultura e a técnica a serviço delas. Algo para refletirmos sobre a formação de professores tão marcada atualmente por uma racionalidade técnica muitas vezes baseada em aprendizagens mecânicas sem reflexão sobre o contexto.

\section{Sentidos emergentes dos praticantespensantes coautores das 40 horas}

Tomando por base de reflexão e enredamento conceitual a experiência [ênfase adicionada], como aquilo que nos passa, modificando-nos e desenvolvendo sentidos, cremos que a partir dos processos rememorativos realizados com os coautores podemos articular alguns pontos/nós interpretativos à rede sempre crescente de conhecimentos das 40 horas. A experiência inicial vem insurgindo recursivamente nos processos formativos de educadores/as nas mais diferentes regiões do Brasil e de outros países, especialmente quando o desafio de alfabetizar pauta as agendas políticas e interesses comunitários.

Nesse sentido, acreditamos que a força que emana das 40 horas de Angicos, após seus cinquenta anos, decorre em parte da força epistemológica empreendida por seu autor, mas resulta também do modo sempre emergente como os coautores rememoram essa experiência. É pela experiência narrada que vem se formando e ajudando a formar compreensões acerca de processos iniciais de alfabetização, sobre ideários políticos, culturais e sociais pautados na criticidade e no desejo de transformação.

As experiências têm traduzido para diferentes interlocutores pesquisadores, estudantes universitários, professores, agentes sociais - inúmeras possibilidades de amplificar suas práticas tornando-as mais criativas e encarnadas com a realidade em que operam. Por isso mesmo, têm se constituído sempre mais recorrente a busca por 
estas experiências, elas não rememoram somente o acontecimento, mas toda a complexidade de significações, conexões e ligações que foram empreendidas e realizadas para que aquela fosse a experiência de educação marcada para jamais ser esquecida pelos grupos populares de histórias e trajetos tão marginalizados.

Os coordenadores, coordenadoras e educandos, hoje mais experienciados têm podido acoplar às lembranças das 40 horas inúmeros outros dispositivos de força que, igualmente àqueles difundidos em sua gênese (libertação, transformação, emancipação) provocam a racionalidade tradicional reducionista de sociedade, ser humano, educação e escola que, teimosamente ainda sobrevive e determina a vida de muitos. São olhares teimosos e muito ansiosos pela continuidade do diálogo, pelo (re)estabelecimento da escuta sensível dos menos favorecidos, pela ampliação dos círculos e validação do outro como extensão de si mesmo.

Essas e tantas outras sensações estão sempre presentificadas nos relatos rememorativos dos coautores da experiência das 40 horas, pois se assim não o fosse, como se explicaria o fato de ser tão intensivamente citada, referenciada e utilizada como possibilidade pedagógica? É no diálogo interativo, complexus, com os coautores que se reforça a natureza epistemológica, política e social da experiência.

Daí ser sempre instigante falar da obra de Paulo Freire porque dá a impressão de que a cada vez que nos aproximamos de uma parte dela, um novo mundo se abre, novas emergências surgem, mas ao mesmo tempo se mostram como parte de algo que não é novo: a luta por educação democrática e popular como direito de todos. Por tudo isso, intuímos que admirar e homenagear Paulo Freire deve ser muito mais do que falar sobre ele e sua concepção de educação, deve significar fazer reviver esta concepção, praticá-la em nosso cotidiano, acreditando e fazendo acreditar que todos somos sujeitos protagonistas e coautores de nosso mundo, de nossas histórias, de nossas relações. 
Apreendemos desse percurso, que a experiência das 40 horas, com seus coautores, para além de sua conceptualidade, tem alimentado a esperança de muitos educadores e educadoras que apostam em processos e práticas educativas mais humanizadoras, declarativas de um mundo, como o próprio Paulo Freire se referiu - menos feio e mais bonito.

\section{Referências bibliográficas}

Certeau, M. (2011). A invenção do cotidiano: artes de fazer. In E. F. Alves (Trad.). (17 ${ }^{\mathrm{a}} \mathrm{a}$ ed). Petrópolis: Vozes.

Freire, P. (1987). Pedagogia do oprimido. (17 ${ }^{\mathrm{a}}$ ed). Rio de Janeiro: Paz e Terra.

Freire, P. (1992). Pedagogia da Esperança: um reencontro com a Pedagogia do Oprimido. ( $8^{\text {a }}$ ed). Rio de Janeiro: Paz e Terra.

Ginzburg, C. (2012). Mitos, emblemas e sinais: morfologia e história. São Paulo: Companhia das Letras.

Halbwachs, M. (1990). A memória coletiva. (L. L.Schaffter, Trad.). São Paulo: Vértice.

Larrosa, J. B. (2002). Nota sobre a experiência e o saber da experiência. Revista Brasileira de Educação, 19(1), 20-28.

Lyra, C. (1996). As Quarenta Horas de Angicos: uma experiência pioneira de educação. São Paulo: Cortez.

Melo, J. F. de, Neto. O que é popular? (2002). Retirado de http://www.prac.ufpb.br/ copac/extelar/producao_academica/artigos/pa_a_2002_o_que_e_popular.pdf.

Sampaio, M. N. \& Silva, F. C. da (2013, setembro). 50 anos de Angicos: memória presente na educação de jovens e adultos. Anais da $36^{a}$ Reunião Anual da Associação Nacional de Pós-Graduação e Pesquisa em Educação (ANPED), Goiânia, GO, Brasil, 36,157-175.

Alves. F., Silva, F. C. da \& Sampaio, M. N. (Entrevistadores/Produtores), \& Núcleo de História e Memória da Educação de Jovens e Adultos (Direção) (2012). Maria Pequena: depoimento [Entrevista com Maria Pequena de Souza, 29 min .WAV]. Natal, RN, Brasil: Residência da entrevistada.

Silva,V. F. da (2013, abril 3). Discurso de agradecimento como representante dos coordenares de círculos de cultura nas 40 horas de Angicos. Disponível em http:// nuhmeja.ce.ufrn.br/nuhmeja.

Thompson, P. (1992). A voz do passado: história oral. Rio de Janeiro: Paz e Terra. 